\title{
Process system analysis on oil processing facility and economic viability from oil well-to-tank
}

\author{
Bilal kazmi ${ }^{1}$. Syed Ali Ammar Taqvi ${ }^{2} \cdot$ Muhammad Naqvi $^{3}$ (D) Suhaib Umer llyas ${ }^{4} \cdot$ Ali Moshin $^{5} \cdot$ Farah Inamullah $^{1}$. \\ Salman R. Naqvi ${ }^{6}$
}

Received: 11 February 2021 / Accepted: 4 May 2021

Published online: 02 June 2021

(c) The Author(s) 2021, corrected publications 2021, 2022

OPEN

\begin{abstract}
Hydrocarbon processing from extraction to the final product is an important aspect that needs an optimised technology for consumption-led market growth. This study investigated real data from the oil processing facility and analysed the simulation model for the entire crude oil processing unit based on the process system engineering aspect using Aspen HYSYS. The study mainly emphasises the process optimisation in processing the hydrocarbon for the maximum yield of the product with less energy consumption. The investigation also includes a thorough economic analysis of the processing facility. The datasets for oil properties are obtained from a modern petroleum refinery. The investigation comprises of varying transient conditions, such as well shutdowns using three oil reservoirs (low, intermediate, and heavy oil). The impact of various conditions, including process heating, well shutdown, oil combinations, presence of water on the production, is analysed. The results indicate that the factors involving crude oil processing are significantly affected by the process conditions, such as pressure, volume, and temperature. The vapour recovery unit is integrated with the oil processing model to recover the separator's gas. The optimisation analysis is performed to maximise the liquid recovery with Reid vapour pressure of 7 and minimum water content in oil around $0.5 \%$. Economic analysis provided an overall capital cost of $\$ 9.7 \times 10^{6}$ and an operating cost of $\$ 2.1 \times 10^{6}$ for the process configuration. The model results further investigate the constraints that maximise the overall energy consumption of the process and reduce the operational cost.
\end{abstract}

Keywords Oil well performance · Aspen HYSYS · Process system optimisation · Vapour recovery unit

\section{Introduction}

Energy is one of the essential constituents of any socioeconomic structure, and its consumption directly affects economic growth [1, 2]. Energy-intensive applications require an uninterrupted and continuous supply either in renewable or non-renewable [3]. Due to the slow depletion of fossil fuels, the world is gradually shifting towards renewable, sustainable, and clean energy sources. However, a tremendous increase in the exploration of oil and gas has also been noticed in the last decade due to the promising outcomes and elevation in the market demand. The global energy demand is still highly dependent on petroleum production.

A complete petroleum production chain consists of geological surveys, extraction, refining, and transportation

$\triangle$ Muhammad Naqvi, raza.naqvi@kau.se |'Department of Applied Chemistry and Chemical Technology, University of Karachi, Karachi, Pakistan. ${ }^{2}$ Department of Chemical Engineering, NED University of Engineering and Technology, Karachi, Pakistan. ${ }^{3}$ Department of Engineering and Chemical Sciences, Karlstad University, Karlstad, Sweden. ${ }^{4}$ Institute of Hydrocarbon Recovery, Universiti Teknologi PETRONAS, 32610 Seri Iskandar, Perak Darul Ridzuan, Malaysia. ${ }^{5}$ Technical University of Crete, Chania, Greece. ${ }^{6}$ School of Chemical and Material Engineering, National University of Sciences \& Technology, Islamabad, Pakistan. 
[4]. Petroleum productions mainly rely on naturally occurring energy resources [5-7]. Organic matter generally consists of rich gas and crude oil, the primary energy production source [8]. Many liquid-based fuels can be refined from crude oil for different applications [9]. However, environmental considerations must be considered without damaging the environment for using fossil fuel combustion to produce energy [10].

The oil reservoirs contain hydrocarbons, but many inorganic chemicals, including $\mathrm{CO}_{2}, \mathrm{~N}_{2}, \mathrm{H} 2 \mathrm{~S}$, etc. These inorganic constituents must be removed to commercialise the petroleum products for different applications [11]. The first phase of the petroleum industry is to perform detailed exploration-based geological surveys at various locations. Drilling procedures and a careful analysis of the oil reserve are performed in the next phase by analysing the exploration [12-15]. The extraction of oil from the well and the preliminary phase separation processes are implemented after developing the drilling facility. The upstream oil production and the stabilisation of oil and gas commence in this phase $[16,17]$. This process separates crude oil, gas, and water from the feed mixture. Then, it processes them into marketable products and byproducts, whereas few inorganic and harmful contaminants are separated initially and disposed of in an environmentally acceptable manner. A schematic of the oil processing facility from the reservoir to the transportation is shown in Fig. 1

It is necessary to analyse complete process parameters before final design and commissioning of the oil facility. During the extraction process, the oil facility's overall production may change with time [18] due to the change in oil composition, gas, and water in the reservoir.

The production of oil can be closed during well shutdowns, breakdowns, or maintenance works. The total production can also be reduced due to the imposed constraints [19]. Therefore, the processing facility should be flexible to achieve maximum performance at any given time. The flexibility of the system can easily be tested by performing computational analysis or process simulations. It is a significant way to analyse production constraints using sensitivity and performance analysis, and measures can be taken based on a smooth production process. The process simulation has become an essential tool for designing, scale-up, and optimising chemical processes [20]. The primary advantage of process simulations is facilitating the engineering team to successfully execute repetitive and complex tasks in a relatively shorter time.

Qeshta et al. [21] performed a parametric study for sweetening liquefied-sour-gas using Aspen HYSYS. It was concluded that the design specification could be maintained if the concentration of $\mathrm{H}_{2} \mathrm{~S}$ in sweet LPG is under 0-10 ppm permissible limit. Martinovic et al. [22] used Aspen plus to simulate and analyse techno-economically two alternative ways for processing used oil to make biodiesel. In another study, Tran et al. [23] performed simulations on Aspen HYSYS for techno-economic analysis of biodiesel production from grease trap waste and reported promising results.

The presented study analyse process design, operation, and monitor process performance of up-stream oil-production facility. To the author's knowledge, this research is not subjected to investigation yet, hence describing the novelty of this work. Various process configurations are simulated to optimise the production at a minimum energy cost. Aspen HYSYS (V9.0) is utilised in the present research, an important process simulation tool widely used in different studies [24-26]. A systematic study is performed to analyse and optimise different process aspects

Fig. 1 The schematic of the oil processing facility

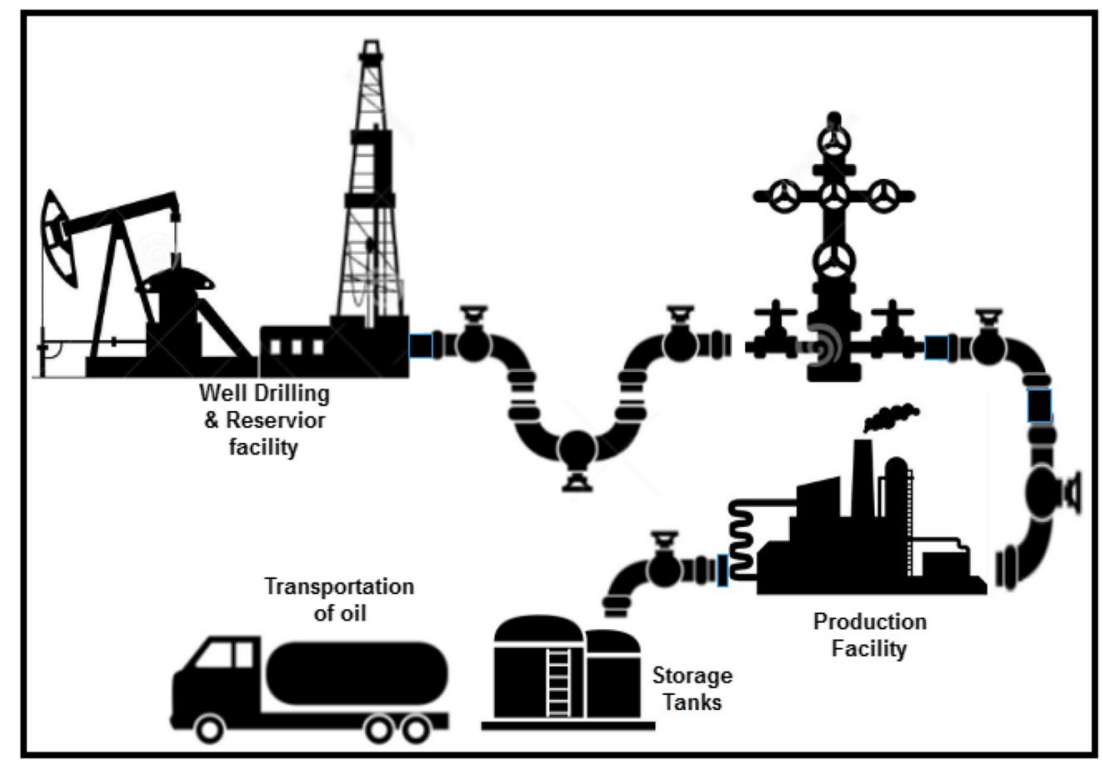


and developed a rigorous optimised process model. The case data is obtained from one of the renowned petroleum refineries in Pakistan. The emphasis is on the major design challenge in the oil-field during the blending of different oils and water. The presented specific case study has not been subjected to investigation before, which corresponds to this research's novelty to the author's knowledge. The optimisation and performance analysis incorporated with the economic analysis contributes to understanding the process constraints and their optimisation in oil and gas industries.

This research is focused on the below-mentioned significant contributions:

1. Process configuration of three-stage separation and vapour recovery from the three-stage separator.

2. Optimum pressure/temperature selection for maximum oil recovery.

3. Effect of temperature on various parameters of oil separation and production quality.

4. Performance analysis concerning production state and well shutdowns and optimisation.

5. Economic analysis of the overall development of the processing facility.

\section{Process and operating parameters}

The crude oil processing begins at the drilling wells when the crude is pumped out from the well and routed to the processing facility at certain pressure and temperature. The oil obtained from the wellhead consists of complex mixtures of straight- and branched-chained hydrocarbons, water, and other contaminants. The significant emphasis at this initial stage is to make it suitable for the downstream refinery sector. Hence, a process simulation approach is applied to model the raw oil properties and process constraints for the separation process. In this view, three separate cases were proposed based on the hydrocarbon feed mixture variation to illustrate the distinct conditions and their effect on the processing. Case-l gives details about the oil mixture composed of heavy crude oil having higher viscosity and API less than $20^{\circ}$; case-II describes the intermediate type of oil mixed with API higher than $20^{\circ}$. However, less than $40^{\circ} \mathrm{C}$ and Case-III depict the lighter crude oil having a lower viscosity than the heavy crude oil and API slightly higher than $40^{\circ}$. Table 1 illustrates the composition of the oil mixtures for each case, and Table 2 represents their properties.

The combination of oil and water in the production units and their variations are incorporated in the process model to obtain tangible results, shown in Fig. 2. The fluctuation of water content in 3 types of oil has also been
Table 1 Feed Composition of the oil from the wellhead

\begin{tabular}{llll}
\hline Component & Case-I & Case-II & Case-III \\
\hline Nitrogen $\left(\mathrm{N}_{2}\right)$ & 0.57 & 0.34 & 1.67 \\
Carbon dioxide $\left(\mathrm{CO}_{2}\right)$ & 2.46 & 0.02 & 2.18 \\
Methane $\left(\mathrm{CH}_{4}\right)$ & 36.37 & 34.62 & 60.51 \\
Ethane $\left(\mathrm{C}_{2} \mathrm{H}_{6}\right)$ & 3.47 & 4.11 & 7.52 \\
Propane $\left(\mathrm{C}_{3} \mathrm{H}_{8}\right)$ & 4.05 & 1.01 & 4.74 \\
Isobutane $\left(\mathrm{i}-\mathrm{C}_{4} \mathrm{H}_{10}\right)$ & 0.59 & 0.76 & 0 \\
n-butane $\left(\mathrm{n}-\mathrm{C}_{4} \mathrm{H}_{10}\right)$ & 1.34 & 0.49 & 4.12 \\
Isopentane $\left(\mathrm{i}-\mathrm{C}_{5} \mathrm{H}_{12}\right)$ & 0.74 & 0.43 & 0 \\
n-pentane $\left(\mathrm{n}-\mathrm{C}_{5} \mathrm{H}_{12}\right)$ & 0.83 & 0.21 & 2.97 \\
n-Heptane $\left(\mathrm{C}_{7}\right)$ & 1.62 & 1.16 & 1.38 \\
C & 47.96 & 56.85 & 14.91 \\
Total & 100 & 100 & 100 \\
\hline
\end{tabular}

included in Fig. 2 at five production units. These Production states classify the water and oil content in various proportions from production states 1 to 5 illustrates the consecutive increase in water content and a decrease in oil content with the last stage of production marks the maximum water content.

\section{Simulation model}

The simulation's primary goal is to carry out a virtual experiment to separate gas from the oil phase. The separated product can be unrouted to the downstream sector for refining and maximising the profit from hydrocarbon production [25]. Peng-Robinson equation of state is applied to the model as the thermodynamic property package. This state equation is the most appropriate model for hydrocarbon processing and has been applied in previous studies [26-29] for modelling different aspects and constraints of the process. This model's ascendency over other models in the Aspen database is the ability to handle a larger range of temperature and pressure and the largest database of binary interaction parameters for a wide range of components. The hypothetical components are defined with the help of temperature ranges which automatically generate the range of components for the actual representation of the oil stream. To make the process more realistic, a generalised real-time process condition was selected, detailed in Table. 3.

The simulation scheme starts with a Lumper unit operation model in Aspen HYSYS, which is used to attach multiple feed streams with different compositions and combine them into a single stream. $\mathrm{C} 1$ to $\mathrm{C} 7$ hydrocarbon components are combined in the present study, whereas the heavy components $(C 7+)$ are de-lumped to eight hypothetical cuts. This scheme is executed to observe and 
Table 2 Properties of the modelled oil

\begin{tabular}{llll}
\hline Properties & Case-I & Case-II & Case-III \\
\hline Specific gravity & 0.9594 & 0.92 & 0.799 \\
Molecular weight & 171.4 & - & 46.69 \\
API gravity & $19^{\circ}$ & $23.6^{\circ}$ & $47^{\circ}$ \\
Asphaltene content in oil (fraction) & 0.1688 & - & - \\
Reservoir temperature & $100{ }^{\circ} \mathrm{C}$ & $95^{\circ} \mathrm{C}$ & $119^{\circ} \mathrm{C}$ \\
Saturation pressure & 2950 psia & 2810 psia & 4677 psia \\
Gas to oil ratio $\left(\mathrm{ft}^{3} \mathrm{bbl}^{-1}\right.$ ) & - & 300 & 2.909 \\
Formation volume factor of oil $\left(\mathrm{rB} \mathrm{STB}^{-1}\right)$ & - & 1.16 & 2.704 \\
\hline
\end{tabular}

Fig. 2 Amount and oil and water content at varying production states

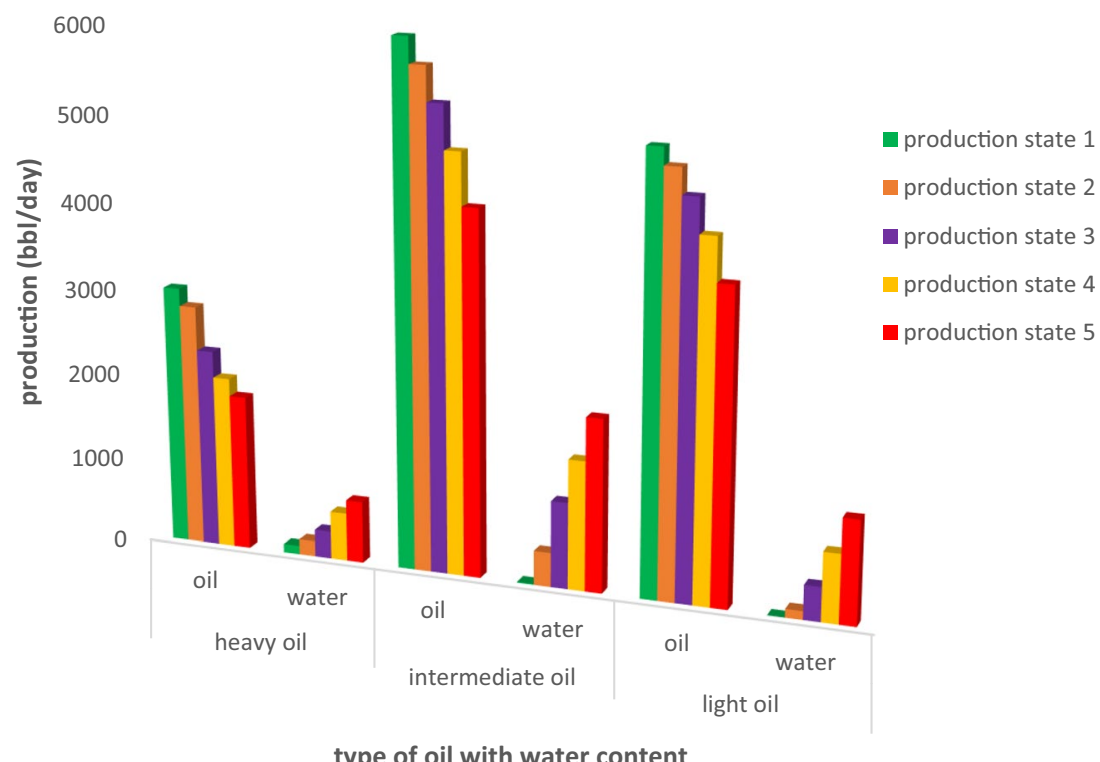

type of oil with water content
Table 3 Properties of the modelled oil

\begin{tabular}{ll}
\hline Parameter & Value \\
\hline Temperature & $15.56^{\circ} \mathrm{C}$ \\
Pressure & $1000 \mathrm{psia}^{-1}$ \\
Oil flow rate & $153,603 \mathrm{lb} \mathrm{h}^{-1}$ \\
Oil volumetric flow rate & $14,110 \mathrm{barrel} \mathrm{day}^{-1}$ \\
Gaseous content flow rate & $14.453 \mathrm{MMSCFD}^{\circ}$ \\
Petroleum property (API) & $58.14^{\circ}$ \\
\hline
\end{tabular}

analyse the combined behaviour of lumped components. Three different oil types based on composition were mixed introduced into the heating unit (Fig. 3). An Inlet heater is introduced to control the stabilised product's vapour pressure. This heater maximises the amount of oil content that remains in the liquid state and enhances the separation process's efficiency. As the temperature is higher, around $65.56^{\circ} \mathrm{C}$, separation increases for oil having higher viscosity and lower API, providing an opportunity to remove impurities, such as water and sand. At this temperature, wax, hydrate, and foam formation and accumulation can be prevented. The stream is at ambient conditions, which increases the viscosity causing difficulty to separate the phases. Therefore, the fluid is heated before the separation.

The oil stream is then introduced with a series of horizontal multistage separators working on the pressure swing principle, removing lighter hydrocarbon components at relatively high pressure. The stream discharge from the bottom goes to the next separator, where further traces of lighter hydrocarbons are removed.

The process ensures to remove the lighter component from the oil mixtures at each stage by maximising the partial pressure of the intermediate components. LP separator is operating near the atmospheric pressure to directly send the oil obtained from the separator to the storage tank.

It was observed from the simulation that the tank oil becomes more stabilised (i.e. higher Reid vapour pressure-RVP, lower API, and high oil production) by increasing the number of separators. The three-staged horizontal separators are considering as the optimal 


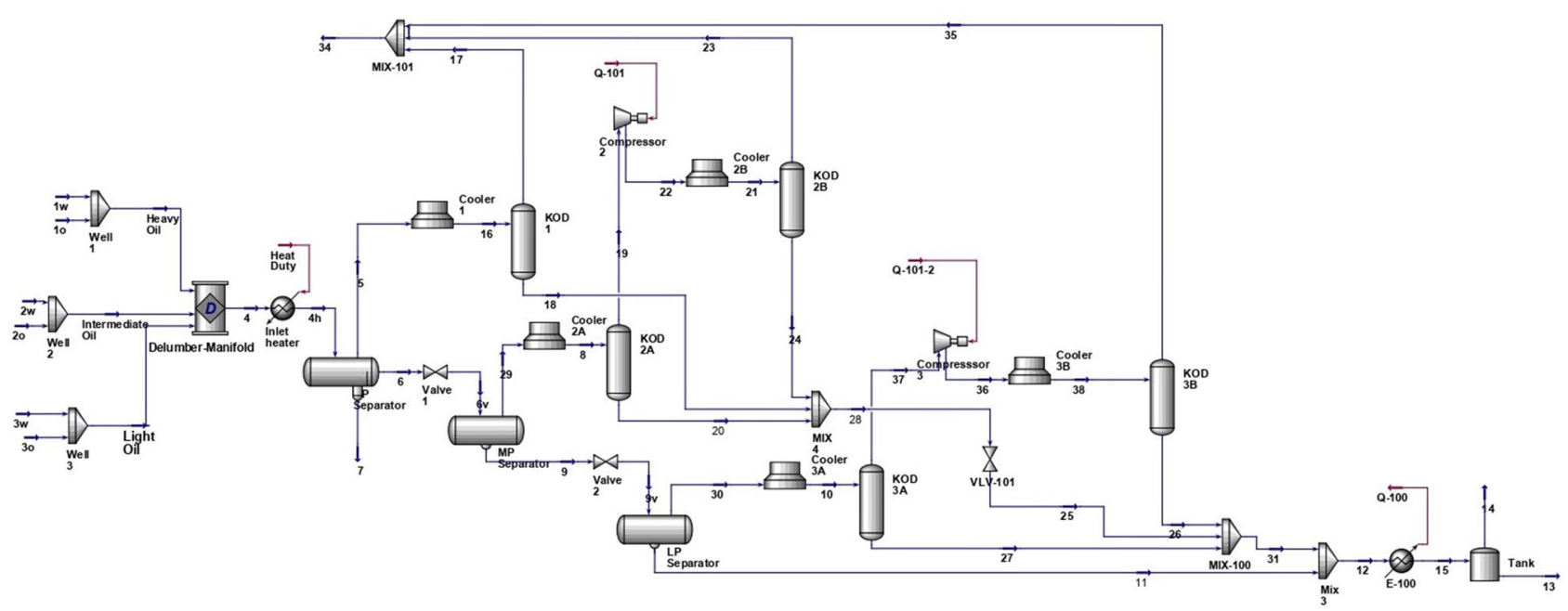

Fig. 3 Process configuration of the oil processing unit combined with vapour recovery unit

separator-stage. In HP (high pressure) separator, all droplets greater than $0.2386 \mathrm{~mm}$ ( $\leq 500$ microns) are settled. This ensures that selected separators are adequately sized, and the water-oil specification is satisfied in the HP separator. The bottom stream from the separators is then sent to the two-phase separator.

The lighter hydrocarbon vapours produced from three separators have high gas to oil ratio. VRU (vapour recovery unit) was further integrated with the process model comprising vertical separators known as knock-out drums (KOD). KODs are added downstream of the vapour outlet of HP (high pressure), MP (medium pressure), and LP (lower pressure) separators. KOD recovers condensates from the vapours and contributes liquid recovery at the tank, shown in Figs. 4. The process consists of the separator adjusted at an optimal value that ensures the high recovery of liquid, less water content ( $\leq 0.5 \mathrm{wt} . \%)$ with less Reid vapour pressure $(\leq 7)$ of the final product.

The vapour stream from the top of $5 \mathrm{KODs}$ is mixed using a mixer and introduced into the fuel gas network for its further utilisation. In contrast, the gas content can be recycled back to the reservoir facility for reinjection into the reservoir. It consists of high pressure, which is essentially vital for the reinjection process. Therefore, the low-pressure gas is further recompressed to elevate the pressure. The obtained water is contaminated and cannot be disposed of directly into the environment; therefore, it is sent to the water processing unit.

The temperature at the outlet of compressors 2 and 3 is approximately $400{ }^{\circ} \mathrm{C}$, which can cause corrosion, pitting, and damaging the pipeline structure due to the presence of $\mathrm{H}_{2}$. Three possible ways can avoid this

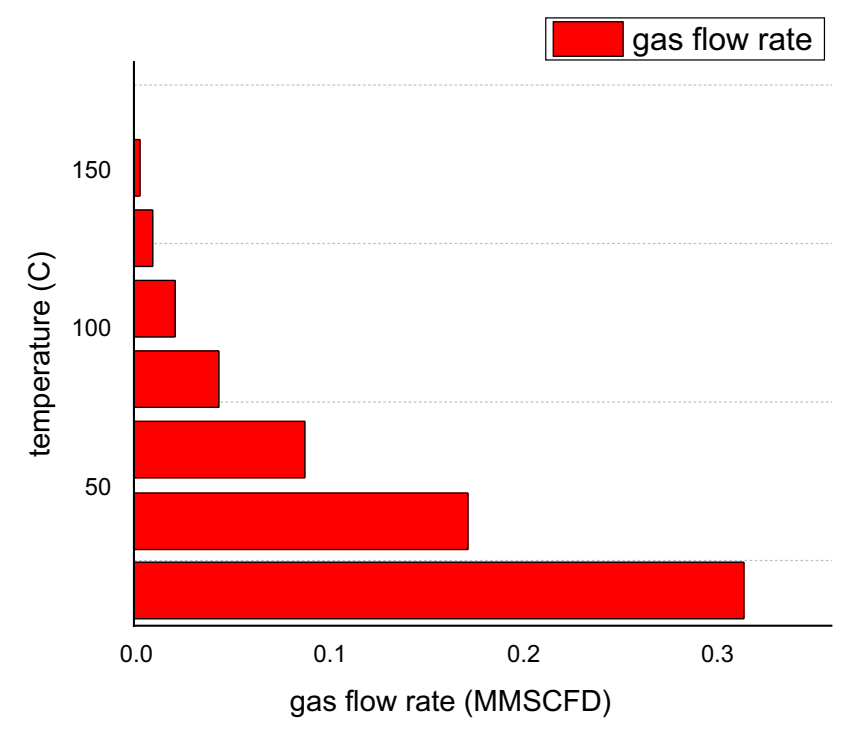

Fig. 4 Effect of temperature on vapour flow rate

challenge; (1) stainless steel material should be used as the material of construction for pipelines which can increase the effective cost of the system, (2) provide a multistage compressor which can also increase capital and operational cost or (3) providing an intermediate cooling system at the compressor outlet with a series of coolers and heat exchanger, which may be an efficient choice to provide the effective and optimal solution of the heat integration system. The finished oil obtained after the separators still contains a considerable amount of impurities in water and salt that has to undergo further treatment and then to storage tanks. 


\section{Results and discussion}

\subsection{Process constraints optimisation}

\subsubsection{Pressure constraint}

The number of stages for the effective separation depends on the well and gas to oil ratio pressure. A twostage process is usually used when the oil to gas ratio is medium, and pressure in the well is lower. In contrast, the three-stage separation process is used for a slightly higher gas to oil ratio with high well pressure [17]. In this study, the maximum gas to oil ratio is set to approximately 4 to control the inter-stage temperature using a three-staged separation operation. Campbell [31] proposed an equation for the number of stages, given in Eq. (1).

$R=\sqrt{((n * P 1) / P)}$

where, $R=$ pressure ratio, $P_{1}=$ stage pressure (high-pressure end), $P=$ tank pressure, $n=$ number of stages excluding tank.

According to Arnold [16], the lowest pressure usually obtained at the lower stages was in the range of 25-50 psia corresponding to the tank pressure. The pressure at any corresponding stage can be evaluated using Eq. (2) [32].

$\operatorname{Pr}=(\operatorname{Pr}-1) / R$

$P r$ is the pressure at stage $r$. Initially, the three-stage separator is developed, and the temperatures and pressure in the unit are optimised with fewer vapours. Then, KODs are added to maximise liquid flow rate recovery. Different cases are simulated in this research work by varying temperature and pressure parameters to maintain high liquid recovery and lower energy utilisation. The pressure limits of separators are HP separator 975-1500 psia, MP separator 230-700 psia and LP separator 10-180 psia [33]. To ensure high oil recovery, the temperature and pressure conditions at the separator inlet are optimised, as shown in Table 4, which provides a final oil having the optimal constraints as illustrated in Table 5.

\subsubsection{Effect of temperature}

Specific conditions are required in the separator for the effective removal of gaseous or lighter components from the oil phase [33]. As the separator inlet temperature is increased, it would result in a high vapour flow rate. Paraffin hydrate forming and foaming issues arise at considerably lower temperature flow assurance since lower temperature reduces the oil viscosity, further affecting the oil
Table 4 Optimal temperature and pressure values

\begin{tabular}{lll}
\hline & Temperature $\left({ }^{\circ} \mathrm{C}\right)$ & Pressure (Psia) \\
\hline HP separator & 121.11 & 1000 \\
MP separator & 118.77 & 240 \\
LP separator & 115.27 & 58 \\
Tank & 15.56 & 14.7 \\
KOD 1 & 34 & 997 \\
KOD 2A & 190 & 240 \\
KOD 2B & 88 & 617 \\
KOD 3A & 34 & 58 \\
KOD 3B & 66 & 887 \\
\hline
\end{tabular}

Table 5 Optimal oil conditions

\begin{tabular}{lc}
\hline \multicolumn{2}{l}{ Optimised oil constraints } \\
\hline Oil [bbl/day] & 10,175 \\
API & 27.22 \\
RVP & 6.832 \\
Water content in oil & 0.0045 \\
\hline
\end{tabular}

flow rate, API, and RVP of the final oil product. Increasing separator temperature would lead to excess vaporisation due to the volatility of the components. The lower temperatures would trigger flow assurance issues due to paraffin, hydrates, and foam. It can be observed from Fig. 4 that an increase in temperature at the HP separator results in removing more vapours and provides stabilised oil. The vapour load on MP and LP separators reduce when the gas/lighter components are removed in the HP separator.

Increasing HP separator temperature lowers the RVP and API, providing more stabilisation to the liquid oil. Hence, it ensures that the lighter components are removed, and resulting in oil (heavy) stable content in MP and LP separators, shown in Fig. 5. It is evident from Fig. 6 that the lower temperatures exhibit higher liquid recovery resulting in higher RVP (depicted in Fig. 6).

The higher temperature also provides an added advantage of separating both continuous phases because the temperature has an inverse impact on the viscosity of oil in comparison to water resulting in more oil because at higher temperature oil and water viscosity decreases, which provides help in separating both the phases as can be seen from Fig. 7. As the temperature increases the oil and water viscosity decreases which increase the phase separation providing us higher water content which can be removed easily from the HP separator. It can be observed from Fig. 8 that the rise in temperature causes more oil recovery compared to the water. The continuous increase in temperature also reduces separator size due to the decrement in the oil's viscosity. Hence, it lowers the liquid residence time, 


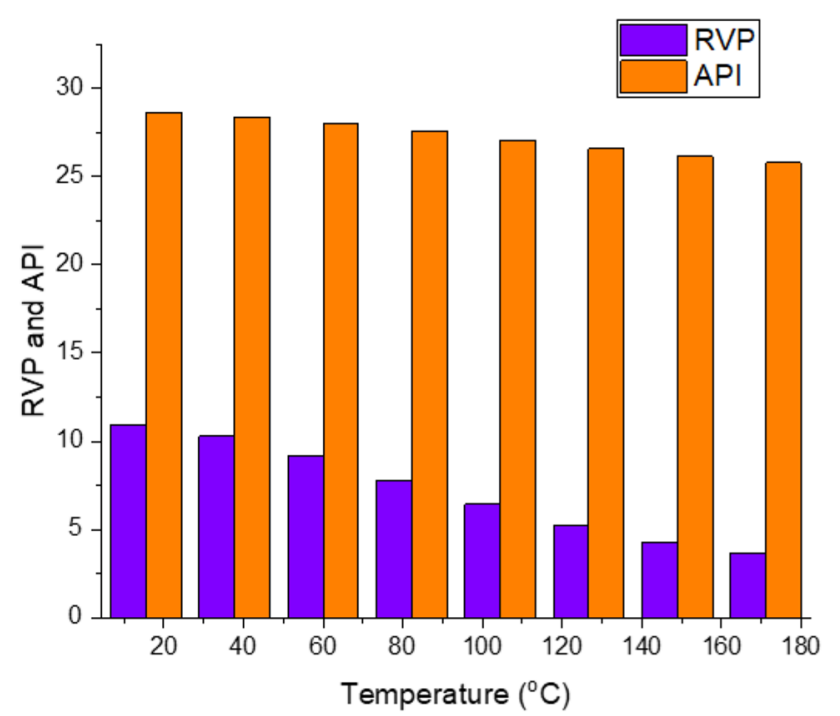

Fig. 5 Effect of temperature on RVP and API

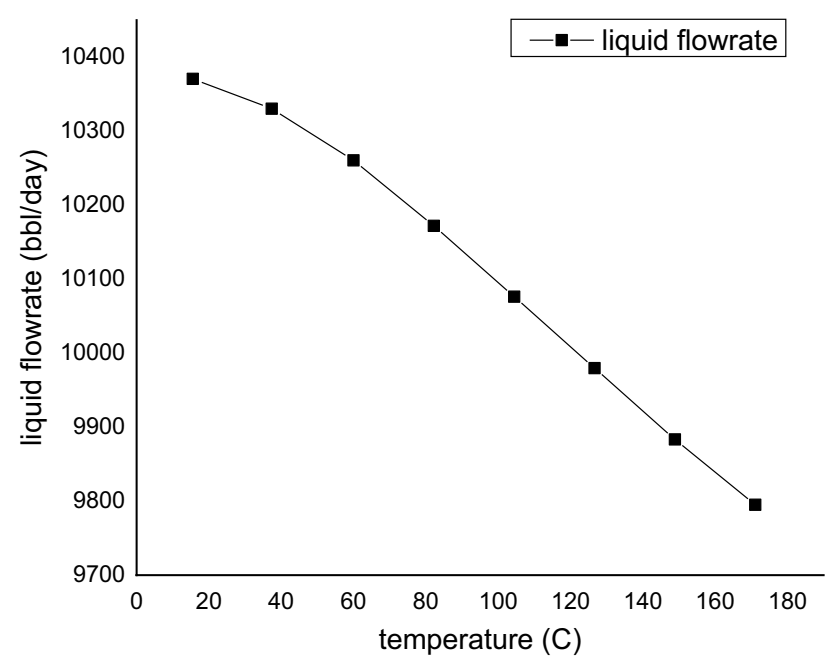

Fig. 6 Effect on oil production concerning temperature

reducing the length of the separator, as shown in Fig. 9. The temperature analysis further ensures that the higher temperature facilitates us with certain advantages: less vapour load in the tank, more stabilised oil, and less energy requirement at the compressors.

\subsubsection{Performance analysis of the production states and well shutdowns}

Production state 1 indicates the lowest water content, whereas production state 5 exhibits the highest water content. Wells 1 and 3 are closed to observe the effect on the overall production process when oil with less API (heavy) and oil having higher API (lighter) are blended [32]. It can be observed from Fig. 10 that the API decreases due to an increase in water content in oil. Similarly, RVP decreases and produces stabilised oil concerning production states. Since shutting Well 3 removes light oil and heavy oil will be produced in the system. Figure 10 shows decreased API and RVP. Similarly, shutting Well 1 removes heavy oil, and the light oil will be produced in the system showing increased API and RVP.

It is observed from Fig. S1 that oil content in the system decreases concerning production states; hence fewer vapours released from horizontal separators will enter the compressors, the decreased vapour flow rate in the compressor will decrease the power consumption of the compressor. It can be observed from Fig. 11 that compressor energy consumption becomes low due to less formation of vapours. The heavy oil system produces fewer vapours. Therefore, it requires less power as compared to the light oil system. The heavy oil has higher water content compared to various production states (shown in Fig. S2). Hence, oil production decreases with production states.

\subsubsection{Pressure analysis on wells under high and low water content}

The pressure analysis is performed on well 1 and well 3 under different conditions of water content. To maximise the recovery of gas and performance of the process, certain adjustments are required in terms of pressure to achieve the maximum oil flow rate and stable RVP. In the present research, two cases were observed. In the first case, well 1 is shut down, causing a decrease in HP Separator and KOD pressure. In the second case, well 3 is shutdown causing HP separator pressure to decrease with KODs and increasing pressure in other separators, i.e. MP and LP. The results illustrate that, in both cases, the pressure is reduced simultaneously with flow rate and lowering the energy consumption by the compressor. In the second case, $\operatorname{KOD}(2 A, 3 A)$, compressor $(2,3)$, cooler $(2 \mathrm{~A}, 3 \mathrm{~A})$ can be bypassed due to the low volatility of oil, which makes the process energy-efficient and hence optimises the process. The detailed configuration can be referred in Fig. S3.

\subsection{Economics analysis}

The capital investments are estimated during project initialisation using available preliminary data. Aspen economic analysis allows the sizing of equipment and generates the estimated equipment cost. The size of equipment is generated based on the operating conditions. This feature allows the estimating of the project cost. The Aspen 
Fig. 7 Effect of viscosity concerning temperature

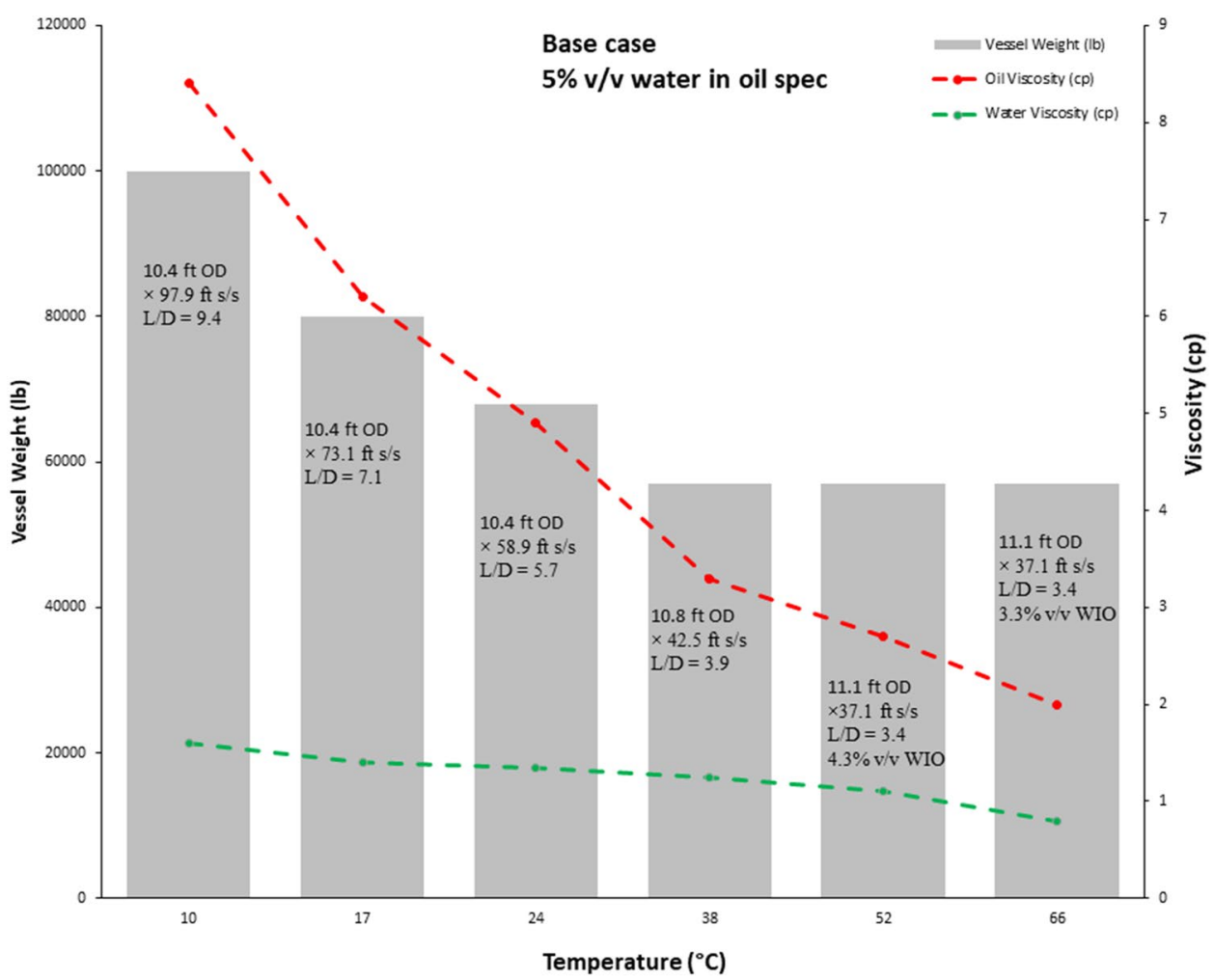

Economic Analyzer optimises the design based on certain aspects. It simulates different scenarios, analyses the effect on essential equipment for the process, and links the data directly to equipment design and cost.

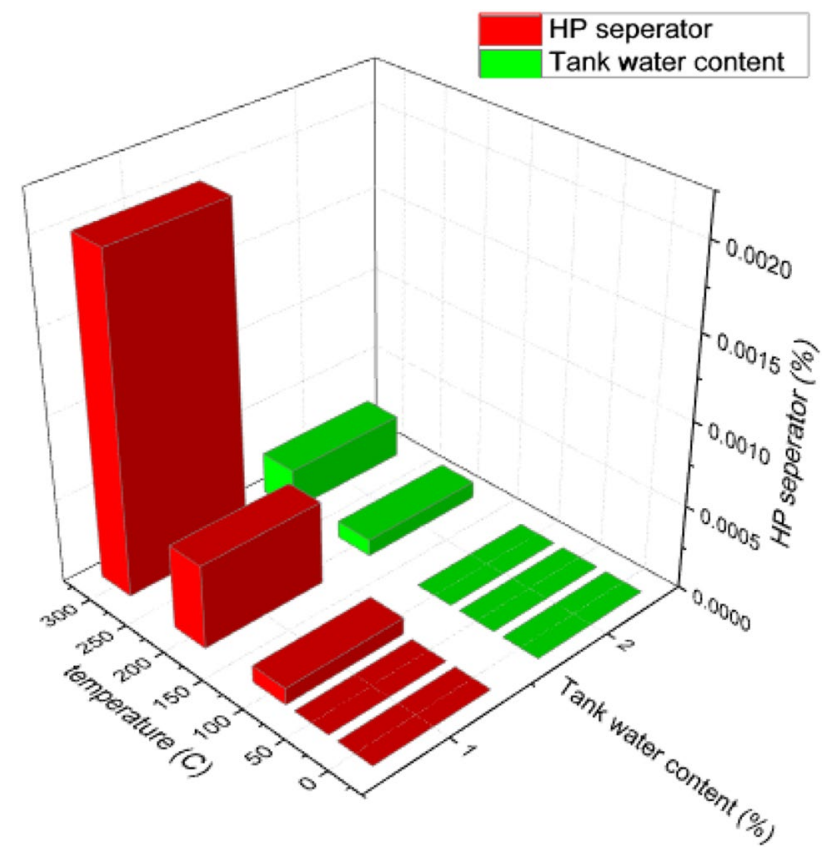

Fig. 8 Effect of temperature on the water content in oil
The economic conditions are based on the utility requirements, raw material cost, equip mental material cost based on the standard design and sizing, process maintenance cost, etc. The total project estimations using Aspen economic analyser are tabulated in Table 6. The optimal process of equipment and energy are selected based on economic analysis.

\section{Conclusions}

The current study provides an approach to solve realtime petroleum production. Three different oil-producing wells data were used to analyse API and RVP due to an increase in water content in oil that would provide a more stabilised product. It results in a more stabilised product. A performance-based analysis was also done results reveal that shutting down well 1 provides the lighter hydrocarbon-based product with higher API and RVP. It can be concluded that to produce more rich content and stabilised products in terms of petroleum quality measuring constraints, and it must shut well 3. Pressure analysis provides an idea of the optimal and stabilised product recovery from different oil wells. Overall, the temperature analysis further ensures that the higher temperature facilitates us with certain advantages: less vapour load in the 


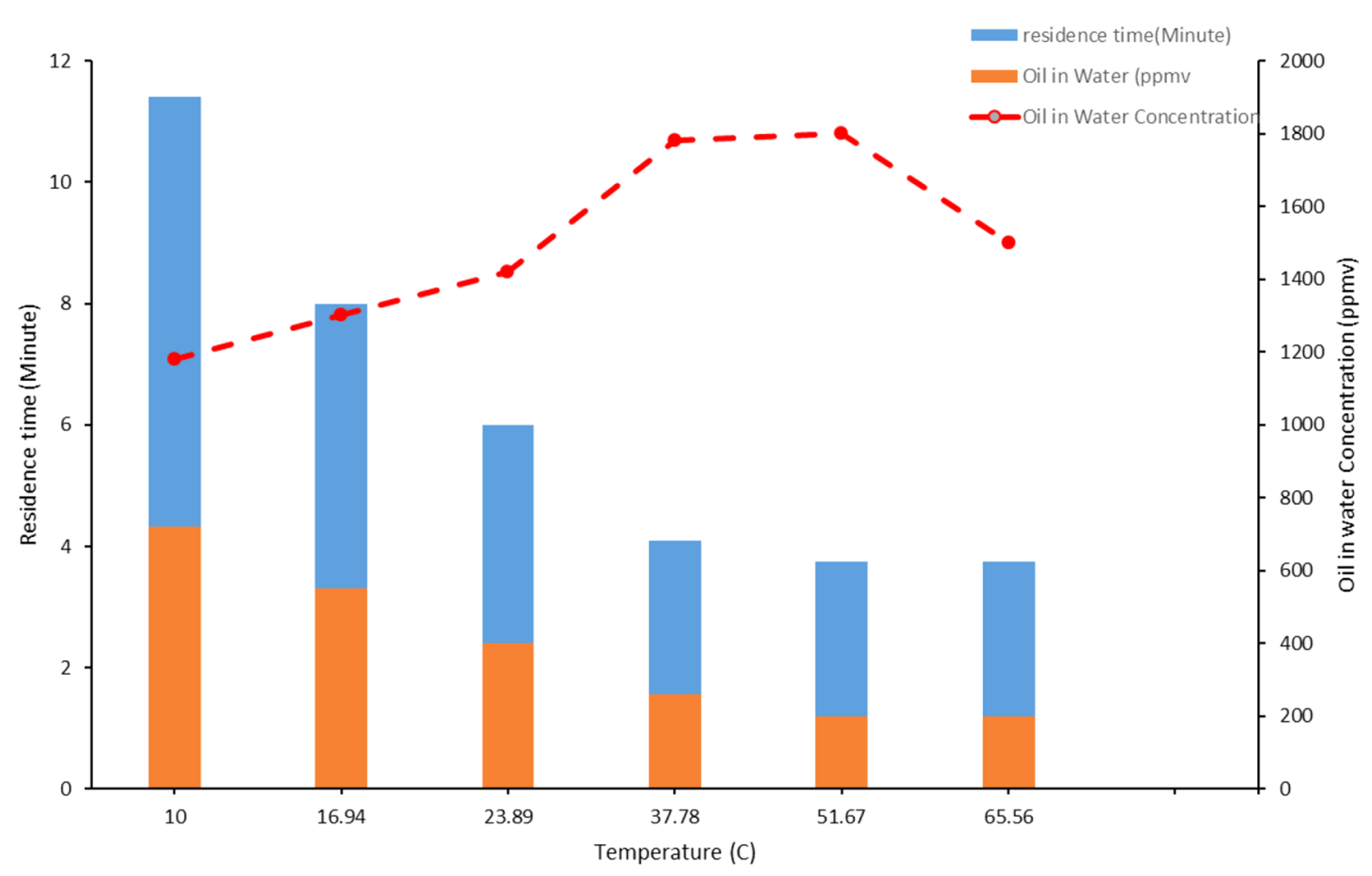

Fig. 9 Effect of temperature on separator size

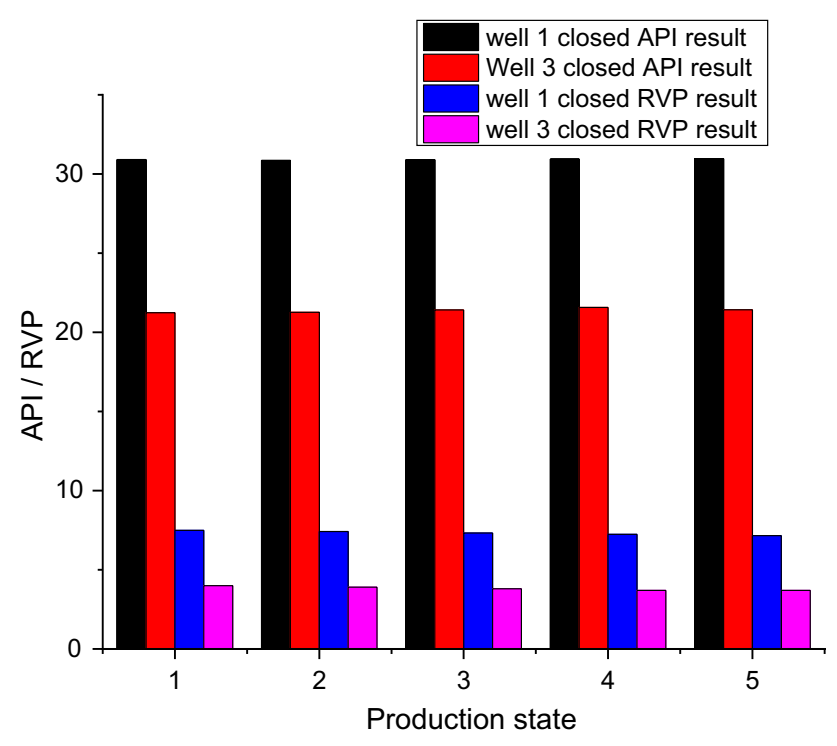

Fig. 10 Effect on API and RVP concerning various production states

tank, more stabilised oil, and less energy requirement at the compressors.

Process optimisation analysis is performed for compressor's energy consumption on production states to provide an energy-efficient solution for maximal production. The economic analysis further provides an analysis-based concept on the actual plant reliability by calculating the

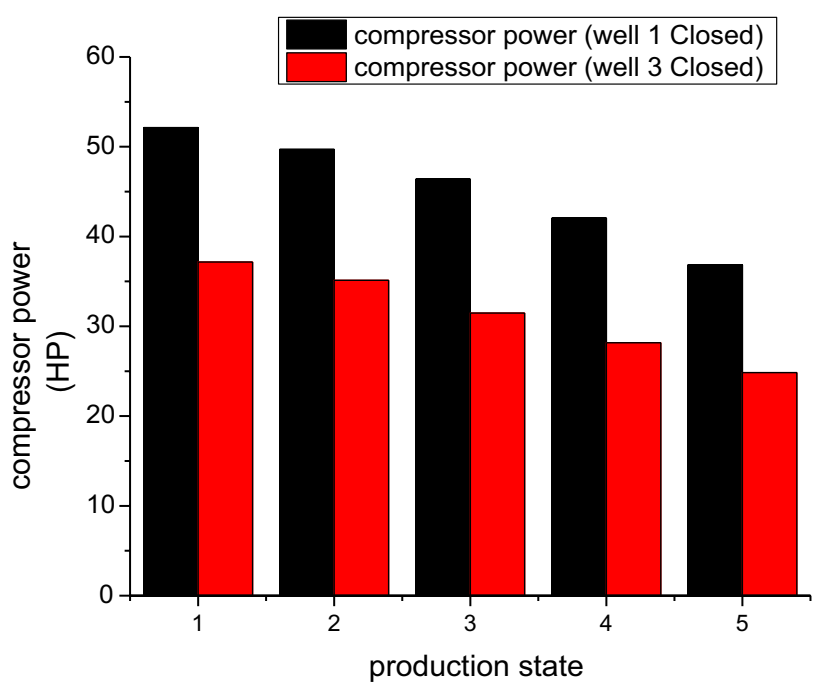

Fig. 11 Compressor power versus various production states

process's various economic aspects. Hence, this developed model signifies and analyses different scenarios to maximise the production and recovery rate on both technical and economic aspects. The proposed simulation model can be integrated with crude distillation units where further analysis can be done to obtain various crude products. Furthermore, it can be utilised for the optimisation of crude oil products. 
Table 6 Economic aspects of the process

\begin{tabular}{ll}
\hline Summary & \\
\hline Plantlife & 5 years \\
Operational hour & $8760 \mathrm{~h} /$ year \\
Rate of return & $20 \% /$ year \\
Constraints & US $\$$ \\
Total capital cost & $9.7 \times 10^{6}$ \\
Total operating cost & $2.1 \times 10^{6}$ \\
Total utility cost & $7.20 \times 10^{5}$ \\
Equipment cost & $2.18 \times 10^{6}$ \\
Total installed cost & $4.05 \times 10^{6}$ \\
\hline
\end{tabular}

The authors intend to further extend this investigation considering heat integration across several units of the petroleum processing industry using several datasets. It is believed that the economic analysis considering all units of the processing facility can be a further step towards more realistic and insightful outcomes.

Acknowledgements The main author would like to acknowledge all authors for the collaboration.

Funding Open access funding provided by Karlstad University.

\section{Declarations}

Conflicts of interest The authors declare that they have no conflict of interest.

Open Access This article is licensed under a Creative Commons Attribution 4.0 International License, which permits use, sharing, adaptation, distribution and reproduction in any medium or format, as long as you give appropriate credit to the original author(s) and the source, provide a link to the Creative Commons licence, and indicate if changes were made. The images or other third party material in this article are included in the article's Creative Commons licence, unless indicated otherwise in a credit line to the material. If material is not included in the article's Creative Commons licence and your intended use is not permitted by statutory regulation or exceeds the permitted use, you will need to obtain permission directly from the copyright holder. To view a copy of this licence, visit http://creativecommons. org/licenses/by/4.0/.

\section{References}

1. Qiao X, Zhao C, Shao Q, Hassan M (2018) Structural characterization of corn stover lignin after hydrogen peroxide presoaking prior to ammonia fiber expansion pretreatment. Energ Fuel Energy Fuels 32(5):6022-6030

2. Zhao C, Qiao X, Cao Y, Shao Q (2017) Application of hydrogen peroxide presoaking prior to ammonia fiber expansion pretreatment of energy crops. Fuel 205:184-191
3. Zhao C, Qiao X, Shaoc Q, Hassan M, Ma Z, Yao L (2020) Evolution of the lignin chemical structure during the bioethanol production process and its inhibition to enzymatic hydrolysis energ fuel. Energy Fuels 146:112177

4. Amponsah R, c FK. (2014) Ghana's downstream petroleum sector: An assessment of key supply chain challenges and prospects for growth. Int J Pet Oil Explor 1(1):1-7

5. Casnedi R (2005) Geological characteristics of hydrocarbon reservoirs. In: Encylopedia of hydrocarbon, vol I, pp 85-116

6. Zou C, Tao S, Yang Z, Hou L, Yuan X, Zhu R, Jia J, Songtao W, Gong Y, Gao X, Wang L, Wang J (2013) Geological concepts, characteristics, resource potential and key techniques of unconventional hydrocarbon: on unconventional petroleum geology. Pet Explor Dev 40:413-428

7. Nianyin Li, Jia K, Haotian Z, Weidong T, Yi R (2019) Numerical simulation of scale formation for injection-production units in oil reservoirs. Arab J Sci Eng. https://doi.org/10.1007/ s13369-019-03975-8

8. Festus IO (2018) Fossil fuels and the current fuel reserve in developed and developing countries. Policy 2:5-10. https://doi.org/ 10.11648/j.stpp.20180201.12

9. Manning FS, Thompson RE (1991) Oilfield Processing of petroleum, vol 1-Natural Gas, Published. ISBN: 0-87814-342-2

10. Thring MW (2017) World energy outlook. Electron Power 23(4):329. https://doi.org/10.1049/ep.1977.0180

11. Cooles GP, Mackenzie AS, Parkes RJ (1987) Non-hydrocarbons of significance in petroleum exploration: volatile fatty acids and non-hydrocarbon gases. Mineral Mag 51:483-493. https://doi. org/10.1180/minmag.1987.051.362.03

12. Lake LW, Mitchell RF (2006) Petroleum engineering handbook. Volume II, Drilling engineering. Ed.; Society of Petroleum Engineers, Richardson, TX

13. Kidnay AJ, Parrish WR, McCartney DGA (2006) CRC Press. https:// doi.org/10.1201/9781420014044

14. Farahani ZD, Movaghar MRK (2017) Improving oil recovery using miscible selective simultaneous water alternating gas (MSSWAG) injection in one of the iranian reservoirs. Arab J Sci Eng. https://doi.org/10.1007/s13369-017-2667-z

15. Joly $M$ (2012) Refinery production planning and scheduling: the refining core business. Brazilian J Chem Eng 29:371-384. https:// doi.org/10.1590/S0104-66322012000200017

16. Murrill BJ (1986) Pipeline transportation of natural gas. Dev Pet Sci 18:279-340. https://doi.org/10.1016/S0376-7361(08)70554-5

17. Luo W, Li H, Yong-qing WJ, Wang SZ (2014) A New completion methodology to improve oil recovery for horizontal wells completed in highly heterogeneous reservoirs. Arab J Sci Eng. https://doi.org/10.1007/s13369-014-1417-8

18. Stewart M, Ken EA (2011) Surface production operations : design of oil handling systems and facilities. Elsevier. https://doi.org/10. 1017/CBO9781107415324.004

19. Zou C, Zhao Q, Zhang G, Xiong B (2011) Energy revolution: from a fossil energy era to a new energy era. Nat Gas Ind B 3:1-11. https://doi.org/10.1016/J.NGIB.2016.02.001

20. Roy PS, Amin MR (2011) Aspen-HYSYS simulation of natural gas processing Plant. J Chem Eng C. https://doi.org/10.3329/jce. v26i1.10186

21. Qeshta HJ, Abuyahya S, Pal P, Banat F (2015) Sweetening liquefied petroleum gas (LPG): parametric sensitivity analysis using Aspen HYSYS. J Nat Gas Sci Eng 26:1011-1017. https://doi.org/ 10.1016/J.JNGSE.2015.08.004

22. Martinovic FL, Kiss FE, Micic RD, Simikić M, Tomić MD (2018) Comparative techno-economic analysis of single-step and twostep biodiesel production with supercritical methanol based on process simulation. Chem Eng Res Des. https://doi.org/10. 1016/j.cherd.2018.02.024 
23. Tran NN, Tišma M, Budžaki S, McMurchie EJ, Gonzalez OMM, Hessel $V$ et al (2018) Scale-up and economic analysis of biodiesel production from recycled grease trap waste. Appl Energy. https://doi.org/10.1016/j.apenergy.2018.07.106

24. Nikolaou M (2013) Computer-aided process engineering in oil and gas production. Comput Chem Eng 51:96-101. https://doi. org/10.1016/j.compchemeng.2012.08.014

25. Aspen tech. The Challenge: Adapting to Change, Optimize Business Performance (2017). https://www.aspentech.com/ en/resources/blog/scaling-digitalization-across-the-downs tream-organization

26. Van Wassenhove W (2015) Dynamic simulation of gas processing plant. In: Handbook of natural gas transmission and processing, pp 467-485

27. Dimian AC, Bildea CS, Kiss AA (2014) Integrated design and simulation of chemical processes. Elsevier

28. Kazmi B, Haider J, Abdul M, Saeed S, Raza M, Lee M (2019) Heating load depreciation in the solvent-regeneration step of absorption- based acid gas removal using an ionic liquid with an imidazolium-based cation. Int J Greenh Gas Control 87:89-99. https://doi.org/10.1016/j.ijggc.2019.05.007
29. Haider J, Qyyum MA, Kazmi B, Zahoor M, Lee M (2019) Simulation study of biomethane liquefaction followed by biogas upgrading using an imidazolium based cationic ionic liquid. J Clean 231:953-962

30. Cengel YA (2014) Heat and mass transfer: fundamentals and applications. McGraw-Hill Higher Education

31. Campbell JM (2014) Gas conditioning and processing. Volume 1: The basic principles, ISBN 978-0-9703449-2-2

32. Suleiman B, Abdulkareem AS, Abdulsalam YO, Musa U, Kovo AS, Mohammed IA (2016) Thermo-economic analysis of natural gas treatment process using triethanolamine (TEA) and diethanolamine (DEA) as gas sweeteners. J Nat Gas Sci Eng 36:184-201. https://doi.org/10.1016/J.JNGSE.2016.10.023

33. Stewart $M$ (2008) Chapter 4-three-phase oil and water separators. In: Stewart M (ed) Arnold KBT-G-LAL-LS. Gulf Professional Publishing, Burlington, pp 131-174. https://doi.org/10.1016/ B978-0-7506-8979-3.00004-0

Publisher's Note Springer Nature remains neutral with regard to jurisdictional claims in published maps and institutional affiliations. 